\title{
Why People Keep Using Knowledge Management Systems: A Causal Analysis of Continuance Behavior
}

\author{
Eric J. Tucker ${ }^{1}$ and Tim Kotnour ${ }^{2}$ \\ ${ }^{1}$ United States Air Force Academy, USAF Academy, Colorado \\ ${ }^{2}$ University of Central Florida, Orlando, Florida \\ eric.tucker@usafa.edu \\ timothy.kotnour@ucf.edu
}

\begin{abstract}
This study examines the factors that cause a person to become a continuous user of a knowledge management system by examining continuance behavior. Continuance behavior is the decision to continue using a product after initial use. The data for this study were obtained using an online survey. The results were analyzed using partial least squares structural equation modeling. Six main hypotheses were developed which resulted in the evaluation of fourteen hypotheses. The results show that the technological features of a knowledge management system positively influence a user's evaluation with limited influence from the system's community features. The results produced a $58 \%$ coefficient of determination for knowledge management systems continuance intention and $37 \%$ for knowledge management systems continuance behavior. This investigation serves as a foundation for further research on the continuance usage of knowledge management systems. It addresses the needs of practitioners by examining which conditions they can manage to increase the purposeful use of their organizations' knowledge management systems. The study also addresses the needs of academia by expanding the literature on continuance behavior of knowledge management systems.
\end{abstract}

Keywords: Continuance Behavior, Expectation Disconfirmation Theory (EDT), Government, KMS, Partial Least Squares (PLS), Structural Equation Modeling (SEM), Survey

\section{Introduction}

A knowledge management system (KMS) is an information system designed to facilitate the storage, retrieval and transfer of knowledge (Alavi and Leidner, 2001; Argote, McEvily and Reagans, 2003). A KMS also involves interaction between people, processes and technology (Bolisani and Handzic, 2014). An information system is a platform that enables an individual and organization to collect, store, process, and transfer information (Lehaney, Lovett and Shah, 2011). Organizations use KMSs as the foundation for the technological component of knowledge management, consisting of people and processes (Alavi and Leidner, 2001). Previous KMS studies focused on describing the critical features of KMSs (Alavi and Leidner, 2001; Hansen, Nohria and Tierney, 1999). Researchers have noted that organizations need to evaluate whether invested resources are being used effectively to improve performance and create a competitive advantage (Krogh, Nonaka and Aben, 2001; O'Dell and Grayson, 1998). Kalling (2003) proposed that organizational KMS efforts may not be directly linked to a performance outcome based on profit but may be linked to a performance outcome if different metrics are considered. Kalling (2003) suggested that knowledge in an organization is not used widely again after initial use. Heisig, et al. (2016) suggested that more research is needed to understand the link between the use of KMSs and productivity. Nisar, et al. (2019) suggested that increased activity using the collaborative dimensions of a KMS coupled with improved knowledge quality in the system results in improved knowledge sharing; however, the impact on productivity is not consistent. These and other efforts highlight the importance of understanding how individual participation leads to KMS contributions (Ardichvili, 2008). Addressing the nature of KMS implementation in organizations is a promising area for study (Wang and Wang, 2016).

Because of the growing evidence that KMSs can lead improve performance, it stands to reason that studies should be available to support practitioners and researchers in this endeavor. However, when examining the existing literature, the following information is lacking: First, it is unclear why KMSs are often underutilized. Second, there is little research on the connection between using a KMS and performance at any level of the organization (Heisig, et al., 2016). While both areas are of interest, this research focuses on understanding system use.

Organizations have experienced a high level of KMS failures. According to Smith, Mills and Dion (2010), as many as $84 \%$ of KMS projects have no significant effect. Malhotra's (2005) research indicates failure rates as high as $70 \%$. The reasons for these failures vary. However, one area that has been addressed is a lack of individual 
engagement (Ardichvili, 2008; Heisig, et al., 2016). Given the lack of individual engagement, organizations need to determine what influences individuals to regularly use KMSs.

Given the ineffectiveness of KMS projects, it is helpful to understand the link between KMS projects and KMS use (He and Wei, 2006; Lin and Tseng, 2005; Tseng, 2008; Small and Sage, 2006). Increasing individual use of a KMS ultimately leads to organizational improvement. The research on the use of information systems is well established and focuses on conditions that influence an individual's initial decision to use an information system (Davis, 1989; Venkatesh, et al., 2003). Another area of information-systems research focuses on determining what influences a user's decision to continue using a technology after initial adoption (Bhattacherjee, 2001). Users who incorporate a KMS into their work routine can enhance individual and organizational performance. Organizations that understand what influences their workers can improve their KMSs to encourage engagement. This study addresses an individual's intention to use and the actual use of, a KMS after initial adoption. There are a limited number of studies on KMS use after initial adoption, also known as continuance (Chen, 2007; He and Wei, 2006, 2009).

\section{Background}

\subsection{Knowledge Management System}

A KMS is an information system designed to facilitate the creation, storage, retrieval and transfer of knowledge (Alavi and Leidner, 2001; Argote, McEvily and Reagans, 2003). The primary purpose of a KMS is to support the knowledge-management activities of individuals in the organization to improve their performance. Although KMSs can take different forms, there are four common features: collaboration, repositories, process codification, and knowledge directories (Maier, 2007).

Collaborative tools increase the flow of knowledge between individuals in the organization by improving communication. Collaborative tools function better when individuals know each other and develop trust (Prusak and Cohen, 2001). Applications that support collaboration include email, chat, discussion boards and web conferencing.

Many KMSs act as a repository by collecting knowledge from individuals that others can access and reuse (Earl, 2001). The knowledge captured is typically context and domain specific. For a repository to be successful, individuals must be willing to contribute and make their knowledge explicit. Furthermore, as individuals contribute to the repository, a process must be in place to maintain the quality of the knowledge (Alavi and Leidner, 2001; Earl, 2001; Gold, Malhotra and Segars, 2001).

Process tools allow an organization to codify processes, work practices, procedures and other improvements within the KMS to improve organizational performance (Binney, 2001; Earl, 2001). Process tools are consistently updated through after-action reviews, lessons-learned sessions, and benchmarking of external organizations. Process tools augment decision-making by providing the most relevant practices.

Directory applications allow individuals to develop profiles and make them available to the entire organization (Earl, 2001). All organizational members are encouraged to create accurate profiles and share knowledge when contacted by fellow members.

This study examines a KMS that incorporates collaboration, repository, and process features to explore how an individual becomes a continuous user. This study is designed to help practitioners understand why individuals do not use a KMS consistently, which makes the system ineffective and results in project failure (Heisig, et al., 2016; Malhotra, 2005). This study examines systems-acceptance research that addresses an individual's initial acceptance of technology and some follow-up-use (Davis, 1989) and continuance research, which focuses on the effectiveness of the follow-up use of technology (Bhattacherjee, 2001). The goal is to understand what drives an individual to use a KMS continuously.

\subsection{Systems-Acceptance and Continuance Research}

Systems-acceptance research primarily addresses an individual's initial acceptance of a given technology (Davis, 1989). In organizations, individuals face an initial decision as to whether to accept a new technology. Sometimes, they must accept the new technology involuntarily (Goodhue and Thompson, 1995). However, users do have a 
choice in their follow-up responses. The follow-up response after initial acceptance is known as post-acceptance or continuance.

In information-systems research, continuance makes information-system use effective. Information systems that are continuously used can significantly impact an organization (Cooper and Zmud, 1990; Kwon and Zmud, 1987). However, users' continuance behavior is uneven. Some will continue to use a system regularly and others will choose to restrict their use.

Continuance is evaluated from two perspectives. One perspective examines continuance behavior as an extension of initial acceptance (Mathieson, 1991; Taylor and Todd, 1995a). The other approach examines continuance as post-confirmation of the initial decision (Tiwana and Bush, 2005). The first approach understands continuance in terms of the same factors that led to initial acceptance. The continuance decision via initial acceptance is evaluated by numerous approaches, including innovation diffusion theory (Rogers, 2003), the technology acceptance model (Davis, 1989), the theory of planned behavior (Ajzen, 1991; Taylor and Todd, 1995a) and social cognitive theory (Compeau and Higgins, 1995). These approaches assume that the same characteristics that explain initial acceptance also justify continuance.

Continuance results from different psychological conditions (Bhattacherjee, 2001; Tiwana and Bush, 2005). Continuance as post-confirmation of the initial decision suggests that initial acceptance does not guarantee continued use. Expectation disconfirmation theory is used to examine continuance behavior (Oliver, 1980). Disconfirmation, satisfaction, and perceived usefulness are the three variables of expectation disconfirmation theory. This approach requires an individual to compare his or her expectations of an experience with the reality.

Bhattacherjee, Perols and Sandford (2008), examine the differences between early and late adopters of information systems using expectation disconfirmation theory. Bhattacherjee (2001) developed a model of information-system continuance based on expectation disconfirmation theory. Expectation disconfirmation theory is rooted in consumer-behavior research and is extended into the context of information systems. One of the key findings of the Bhattacherjee (2001) information system continuance study is that a user may discontinue using a system after initially accepting it.

\subsection{Continuance Model}

The information systems continuance model, which is grounded in consumer-satisfaction research, is based on expectation disconfirmation theory (Anderson and Sullivan, 1993; Oliver, 1993). Expectation disconfirmation theory suggests that an individual's decision to repurchase or use a product is based on the confirmation of an initial expectation, the perception of the product's performance and the level of satisfaction with the product. A purchaser's initial expectation is seen as influencing satisfaction. In expectation disconfirmation theory, satisfaction is a crucial variable driving repurchase intention.

Continuance intention is similar to repurchase intention for a consumer product. First, a consumer purchases an item; this is the initial decision. Second, a consumer develops an initial opinion of that purchase. Third, based on their subsequent experience compared with their initial opinion, a consumer may decide to repurchase the product. In the information-systems context, systems acceptance is the initial decision that weighs heavily on future use. If the initial experience aligns with or exceeds the expectation of that experience, then the user is likely to continue using the system.

The information systems continuance model shows that an individual's intention to continue using an information system is influenced by their satisfaction and perception of its usefulness (Bhattacherjee, 2001). Perceived usefulness and satisfaction are both influenced by disconfirmation. Disconfirmation involves comparing a user's previous use to a user's current use. Additionally, perceived usefulness measures a user's post-usage acceptance, which is a stronger indicator of future use than user satisfaction (LaTour and Peat, 1980). Jennex and Olfman (2006) addressed the variables of intent to use/perceived benefit and satisfaction in the knowledge management success model. Satisfaction is seen as a strong proxy for KMS use, as different users will use a KMS as needed. Nevertheless, use on a frequency-type basis may be infrequent yet the use may be effective. Use/perceived benefit extends the concept of perceived consequences (Thompson, Higgins and Howell, 1991). Perceived consequences are the anticipated outcomes of value based on an individual's actions (Triandis, 1979). Therefore, intent to use/perceived benefit serves as a proxy for understanding whether use will occur in the future (Jennex, 2012). 
Bhattacherjee, Perols and Sandford (2008) proposed an extension of the information systems continuance model by evaluating and elaborating on factors influencing the original model. The extended model incorporates information-technology (IT) self-efficacy and facilitating conditions. These two variables are part of perceived behavioral control as developed in the theory of planned behavior (Ajzen, 1985, 1991). Users' perceptions that their organizations support them are known as facilitating conditions (Bhattacherjee, Perols and Sandford, 2008). Examining facilitating conditions is expected to explain what moves a user from the intention to use the system to actually using it.

Bhattacherjee, Perols and Sandford's (2008) extended model alters the terminology from perceived usefulness to post-usage usefulness to avoid confusion with previously developed initial-acceptance models. The extended model removes the relationship between usefulness and satisfaction because said relationship is not clearly defined. In addition, the extended model adds IT self-efficacy and facilitating conditions. IT self-efficacy addresses an individual's belief that they can use a system based on their understanding. Facilitating conditions address an individual's belief that they have support from their organization to use the information system. This KMS-continuance model examined in this study is shown in Figure 1.

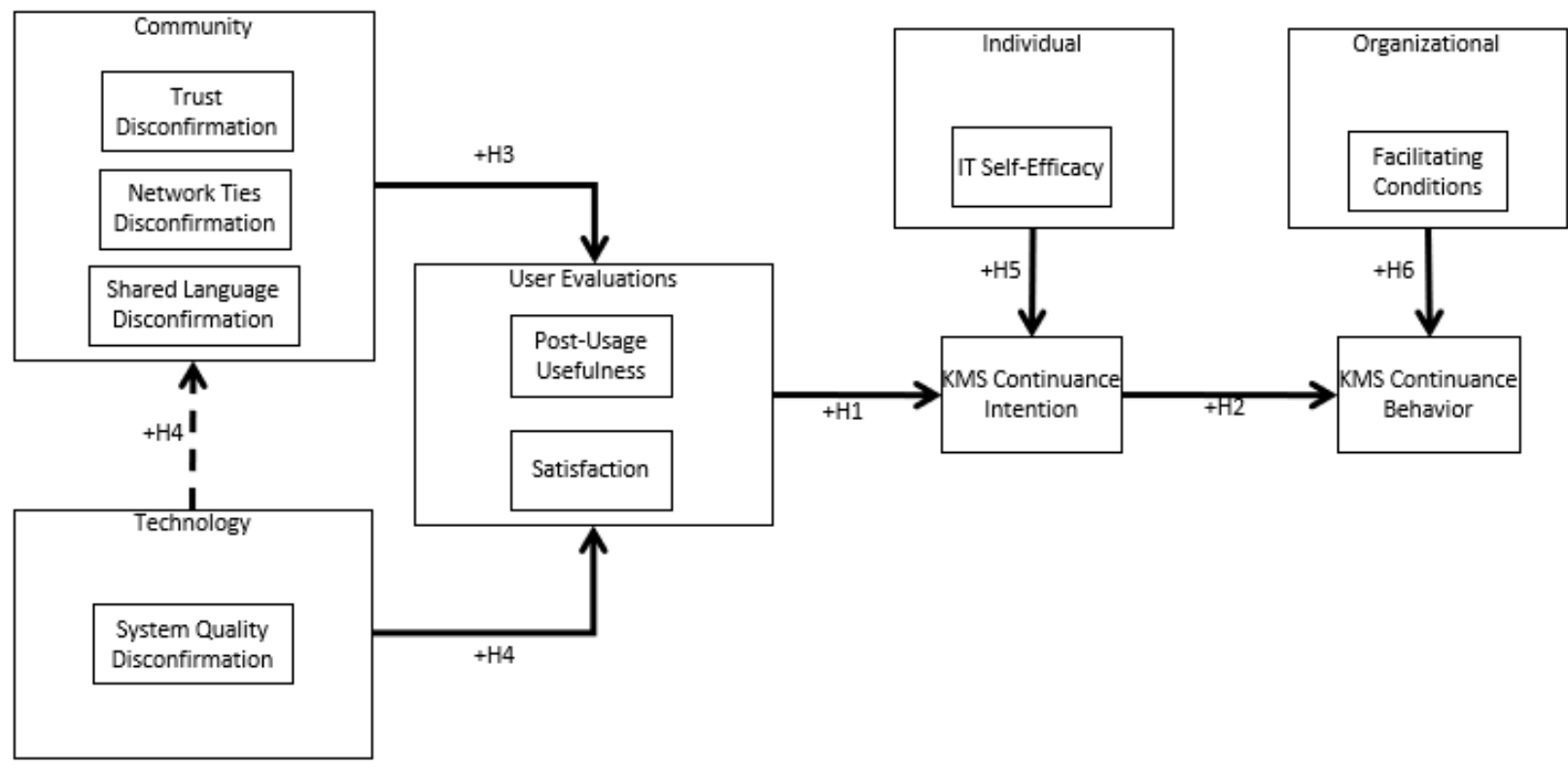

Figure 1: Research Model of Knowledge Management System Continuance

As a result, it is proposed that

(H1) Hypothesis 1: User evaluation is positively related to increased KMS-continuance intention. (H2) Hypothesis 2: KMS-continuance intention is positively related to increased KMS-continuance behavior.

\subsection{Dimensions of Knowledge Management Systems}

As previously stated, knowledge management consists of people, processes and technology. Therefore, KMSs primarily focus on the technology of knowledge management (Alavi and Leidner, 2001). In this research, four dimensions are examined that are expected to be related to user evaluation, continuance intention and continuance behavior. The four dimensions are community, technology, the individual and the organization (Maier, 2007).

Community refers to social interactions' influence on KMS use (Prusak and Cohen, 2001). Community is evaluated through the lens of social capital theory, which suggests that the strength of an individual's relationships leads to social actions (Nahapiet and Ghoshal, 1998). Social capital theory, developed by Nahapiet and Ghoshal (1998), consists of three components: the relational, structural and cognitive levels. The relational dimension of social capital theory consists of trust, norms, obligation and identification. The structural dimension consists of network ties, network configuration and appropriable organization. Finally, the cognitive dimension consists of a shared language and shared narratives. This study hypothesizes that trust, network ties and shared language are related to a user's evaluation of a KMS. 
(H3) Hypothesis 3: Community interaction is positively related to increased user evaluation.

The technological dimension explains how a KMS facilitates and enhances user evaluations. When executed properly, a KMS supports improved processes and decision-making activities (Lucas, 1990). KMSs allow organizations to better manage their processes by creating, storing, transferring and applying new knowledge. In addition, a KMS can facilitate and enhance individual and collaborative activities. Technological attributes can influence an individuals' willingness to use a KMS (Schiuma, Andreeva and Kianto, 2012). The attributes examined include reliability, user-friendliness, accuracy and accessibility. The technology dimension represents the quality of the knowledge, the effectiveness of accessing the knowledge and the ease of interaction.

(H4) Hypothesis 4: The level of technological quality is positively related to increased user evaluation and community interaction.

Organizations provide KMSs to their employees as well as the strategy and resources to use them. Individuals must contribute to the KMS to make its use worthwhile. All knowledge starts with the individual and spreads to others, resulting in new knowledge that the organization can magnify in the KMS (Nonaka, 1994).

Individual and organizational dimensions are modeled using the concept of perceived behavioral control. Perceived behavioral control is the belief that individuals have adequate control over their behavior (Ajzen, 1991). Perceived behavioral control is a multifaceted measure that includes the variables self-efficacy and controllability. Applying a perceived behavioral-control concept to information systems explains individual behaviors in voluntary and involuntary situations (Venkatesh and Davis, 2000). Self-efficacy is an individual's perception of their ability to accomplish a task. IT self-efficacy is an individuals' perception of their ability to operate a technology effectively (Venkatesh, et al., 2003). Controllability is the control individuals perceive themselves as having over the resources needed to accomplish a task.

As noted above, perceived behavioral control has two components: self-efficacy and controllability. Self-efficacy addresses an individual's perception of control and is inwardly focused. Controllability addresses an individual's perception of external control (Bhattacherjee, Perols and Sandford, 2008; Taylor and Todd, 1995b). Bhattacherjee, Perols and Sandford (2008) examined the internal and external aspects of control in the extended information systems continuance model. Venkatesh, et al. (2003) examined IT self-efficacy's influence but found it negligible. While the multiple-measure nature of perceived behavioral control may be unclear, Bhattacherjee, Perols and Sandford (2008) showed that self-efficacy positively influences information systems continuance intention. Controllability, also known as facilitating conditions, positively influences actual use. IT self-efficacy is expected to impact continuance intention, and facilitating conditions are expected to impact continuance behavior.

The organizational dimension encompasses actions by the organization that influence individuals to use a KMS. This organizational dimension is external to the individual and thus out of their control. The organizational dimension is measured by facilitating conditions. Facilitating conditions encompass the following concepts controlled by the organization: supportive leadership, organizational structure and availability of resources. Venkatesh et al. (2003, p.453) defined facilitating conditions as "the degree to which an individual believes the organizational and technical infrastructure exists to support their use of the system."

Facilitating conditions enhance an individual's ability to use a given system. The organization's leadership can support and encourage KMS use by providing external resources, such as training, collaboration time and remote access (Bhattacherjee, Perols and Sandford, 2008; Davenport, De Long and Beers, 1998; Kerno, 2008). Additionally, an organization should reduce unnecessary rules and structures to encourage employees to interact freely and cohesively (Davenport and Prusak, 1998; McKeen, Zack and Singh, 2006). Finally, organizations must reduce and eliminate barriers by integrating and embedding the KMS into daily processes (Wiig, 1997).

(H5) Hypothesis 5: IT self-efficacy is positively related to increased KMS-continuance intention.

(H6) Hypothesis 6: Facilitating conditions are positively related to increased KMS-continuance behavior. 


\subsection{Research Model}

The research model uses concepts and definitions from the KMS and information systems continuance literature. In addition, the approach captures individuals' perceptions of their use of KMSs.

The hypotheses are drawn from the theory that individuals will continually use a system that provides usefulness and satisfaction. The community dimension explains how the strength of individuals' trust, network ties and shared language influences their actions. The technology dimension affects the structural dimension of network ties. Both the community and technology dimensions directly influence users' perceptions of usefulness and satisfaction. These factors subsequently influence users' intention to use the system, which directly affects actual use. Users' intentions to use the system are also influenced by their IT self-efficacy, which affects their confidence in using the system. Finally, users' actual use is influenced by their perception of external support from their organization.

\section{Research Methods}

\subsection{Methods of Analysis}

Partial least squares (PLS) structural equation modeling (SEM) is a useful approach in situations in which theory is not well developed (Wold, 1985). Research on KMSs and information-system acceptance are well established, but their combination is not; thus, PLS is an appropriate analysis method (Cepeda-Carrion, Cegarra-Navarro and Cillo, 2019).

The PLS approach allows the evaluation of the relationship between independent (exogenous) variables, dependent (endogenous) variables and the interrelationship of both. PLS is a SEM approach widely conducted using a two-step process (Chin, 1998; Sosik, Kahai and Piovoso, 2009). The first step is the estimation of the measurement model, which is similar to factor analysis. A measurement model shows how the measurement items relate to their latent variables. A latent variable cannot be observed directly. The measurement model provides reliability information and factor loadings about the latent variable of interest. The second step is the estimation of the structural or path model. The structural model estimates the path coefficients that determine the relationship between independent and dependent variables. The path coefficients indicate the strength of the relationships between variables. PLS generates t-values, $R^{2}$, composite reliability and average variance extracted (AVE).

\subsection{Measures}

The current study emphasizes the KMS characteristics that influence an individual's continued use of a KMS. The variables used are based on previously developed multi-item variables.

The community dimension of a KMS is modeled by three variables-trust, network-ties and shared-language disconfirmation. The disconfirmation approach asks individuals to compare their current experience to their prior expectations regarding said experience (Bhattacherjee, 2001; Oliver, 1980). The three variables and associated measurement items are based on previous research of social capital theory (McKnight, Choudhury and Kacmar, 2002; Nahapiet and Ghoshal, 1998; Tiwana and Bush, 2005). Trust disconfirmation uses six items that measure the competency and benevolence of trust. Network-ties disconfirmation uses three items and shared-language disconfirmation uses two items.

The technology dimension of KMSs is modeled by a single variable-system-quality disconfirmation. Three items compose this variable from previous research (Clay, Dennis and Ko, 2005; McKinney, Yoon and Zahedi, 2002).

Two variables measure a user's evaluation of a KMS: Post-usage usefulness and satisfaction. Post-usage usefulness is measured by four items adapted from Davis (1989) and Bhattacherjee (2001). Satisfaction is measured by three items adapted from Spreng, MacKenzie and Olshavsky (1996) and Bhattacherjee (2001).

The individual dimension of KMSs is measured by IT self-efficacy, which is itself measured by three items (Bhattacherjee, Perols and Sandford, 2008). The organizational dimension of a KMS is measured by facilitating conditions that consist of three items adapted from Bhattacherjee, Perols and Sandford (2008) and Venkatesh et al. (2003). KMS-continuance intention is measured by three items (Bhattacherjee, 2001). KMS-continuance behavior is measured by three items adapted from Bhattacherjee, Perols and Sandford (2008). Five items 
measure demographic data. User comments are collected with two questions. The data-collection model is presented in Figure 2. Table 1 shows the measurement items for the variables used in this study.

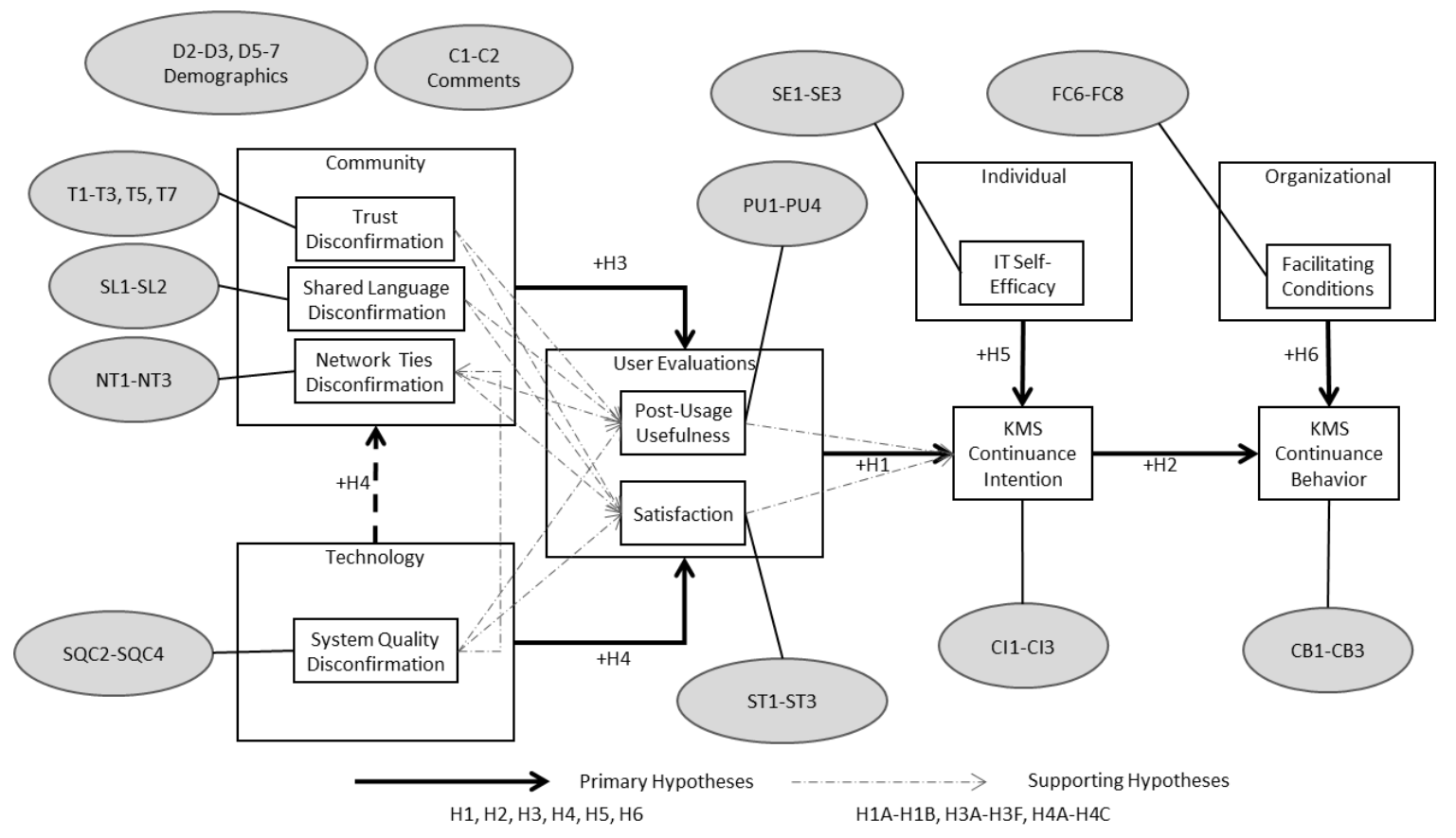

Figure 2: Data-Collection Model

Table 1: Measurement Items of Variables

\begin{tabular}{|l|l|}
\hline \multicolumn{2}{|c|}{ Measurement items of variables: Exogenous (I) and Endogenous (D) } \\
\hline Facilitating Conditions (I) \\
\hline FC6 & My organization provides the time needed to use the KMS. \\
\hline FC7 & My organization's leadership supports the use of the KMS. \\
\hline FC8 & My organization encourages me to integrate the use of KMS into regular processes. \\
\hline Information-Technology Self-Efficacy (I) \\
\hline SE1 & I can perform my job using Air Force Knowledge Now (AFKN) resources without assistance from others. \\
\hline SE2 & I can perform my job using AFKN resources if I have adequate time to complete the job. \\
\hline SE3 & I can perform my job using AFKN using only the online help feature as a reference. \\
\hline KMS-Continuance Intention (I/D) \\
\hline CI1 & I intend to continue to use this KMS in the future. \\
\hline CI2 & My personal intentions are to continue using this KMS to acquire, create, store, or transfer knowledge. \\
\hline \multirow{2}{*}{ CI3 } & $\begin{array}{l}\text { If permitted by my organization, I would like to continue to use this KMS to acquire, create, store or transfer } \\
\text { knowledge. }\end{array}$ \\
\hline KMS-Continuance Behavior (D) \\
\hline CB1 & How many times have you visited AFKN in the last month? 0 | 1-3 | 4-6 | 7-9 | 10-12 | more than 12 \\
\hline \multirow{2}{*}{ CB2 } & What percentage of work do you currently perform using knowledge from the AFKN KMS? \\
\cline { 2 - 3 } & $0 \%$ | 1-10\% | 11-20\% | 21-30\% | 31-40\% | more than 40\% \\
\hline \multirow{2}{*}{ CB3 } & How much time throughout your week do you spend sharing knowledge with the AFKN KMS? \\
\cline { 2 - 3 } & Less than 1 hour | 1-3 | 4-6 | 7-9 | 10-12 | more than 12 hours \\
\hline Network-Ties Disconfirmation (I/D): Compared to my initial membership in this AFKN KMS community, ... \\
\hline NT1 & Members know each other more closely than I expected. \\
\hline NT2 & Members professionally interact (on the KMS) more closely than I expected. \\
\hline NT3 & Members network more often than I expected. \\
\hline
\end{tabular}




\begin{tabular}{|c|c|c|c|c|c|c|c|}
\hline \multicolumn{8}{|c|}{ Measurement items of variables: Exogenous (I) and Endogenous (D) } \\
\hline \multicolumn{8}{|c|}{ Post-Usage Usefulness (I/D) } \\
\hline PU1 & \multicolumn{7}{|c|}{ Using the KMS will increase my productivity (e.g., work is completed faster). } \\
\hline PU2 & \multicolumn{7}{|c|}{ Using the KMS will improve my performance (e.g., makes my work routine better). } \\
\hline PU3 & \multicolumn{7}{|c|}{ Using the KMS will make me more effective (e.g., helps me make better decisions). } \\
\hline PU4 & \multicolumn{7}{|c|}{ I find the KMS to be useful in my job. } \\
\hline \multicolumn{8}{|c|}{ Satisfaction (I/D) - Questions were positioned at intervals throughout the survey and used different scales. } \\
\hline & \multicolumn{7}{|c|}{ How do you feel about your overall experience using AFKN? } \\
\hline ST1 & $\begin{array}{c}\text { Very } \\
\text { Dissatisfied }\end{array}$ & Dissatisfied & $\begin{array}{l}\text { Dissatisfied } \\
\text { Somewhat }\end{array}$ & Neutral & $\begin{array}{c}\text { Satisfied } \\
\text { Somewhat }\end{array}$ & Satisfied & Very Satisfied \\
\hline ST2 & $\begin{array}{c}\text { Very } \\
\text { Displeased }\end{array}$ & Displeased & $\begin{array}{l}\text { Displeased } \\
\text { Somewhat }\end{array}$ & Neutral & $\begin{array}{c}\text { Pleased } \\
\text { Somewhat }\end{array}$ & Pleased & Very Pleased \\
\hline ST3 & $\begin{array}{c}\text { Very } \\
\text { Frustrated }\end{array}$ & Frustrated & $\begin{array}{l}\text { Frustrated } \\
\text { Somewhat }\end{array}$ & Neutral & $\begin{array}{l}\text { Contented } \\
\text { Somewhat }\end{array}$ & Contented & $\begin{array}{c}\text { Very } \\
\text { Contented }\end{array}$ \\
\hline \multicolumn{8}{|c|}{ Shared-Language Disconfirmation (I): Compared to my initial membership in this AFKN KMS community, ... } \\
\hline SL1 & \multicolumn{7}{|c|}{ A common language is used to share ideas more than I expected. } \\
\hline SL2 & \multicolumn{7}{|c|}{ A common set of terms is known by members more than I expected. } \\
\hline \multicolumn{8}{|c|}{ System-Quality Disconfirmation (I): Compared to my initial membership in this AFKN KMS community, ... } \\
\hline SQ2 & \multicolumn{7}{|c|}{ The accuracy of stored knowledge is greater than I expected. } \\
\hline SQ3 & \multicolumn{7}{|c|}{ The ease of using the AFKN interface is greater than I expected. } \\
\hline SQ4 & \multicolumn{7}{|c|}{ Technical support for AFKN interface is better than I expected. } \\
\hline \multicolumn{8}{|c|}{ Trust Disconfirmation (I): Compared to my initial membership in this AFKN KMS community, ... } \\
\hline $\mathrm{T} 1$ & \multicolumn{7}{|c|}{ My trust in other members is greater than I expected. } \\
\hline $\mathrm{T} 2$ & \multicolumn{7}{|c|}{ My belief that other members have good intentions is greater than I expected. } \\
\hline T3 & \multicolumn{7}{|c|}{ My belief in the reliability of others is greater than I expected. } \\
\hline T5 & \multicolumn{7}{|c|}{ My community's general knowledge of the subject matter is greater than I expected. } \\
\hline T6 & \multicolumn{7}{|c|}{ My community's overall capability as an expert source of knowledge is greater than I expected. } \\
\hline T7 & \multicolumn{7}{|c|}{ My trust in this community's ability to protect sensitive material is greater than I expected. } \\
\hline
\end{tabular}

\subsection{Data collection and sample}

In previous studies, KMSs were presented as a combination of human and technical components. In this study, the United States Air Force (USAF) KMS is examined (Bartczak, Turner and England, 2008; Fitzgerald, 2004), specifically the Air Force Knowledge Now (AFKN) System. The USAF has more than 600,000 individuals working for multiple organizations around the globe. The individuals that work in the Air Force are classified as civilians, officers, or enlisted personnel. AFKN consists of 300,000 users organized into knowledge communities. AFKN users may join communities, access repositories, locate experts and perform organizational processes. AFKN use is tracked through web-based metrics. Community owners can customize the structure of the interface for the needs of the users.

AFKN administrators reported that the KMS is used in one of three ways: as a repository, a collaborative platform, or a process tool. The repository approach allows users to find and exchange documents. Any member of AFKN can use the search interface to access the repository of accessible open knowledge. The collaborative approach provides various virtual tools, such as email, chat and conference features. Finally, the process approach allows organizations to embed functions on the AFKN platform used as part of an organization's regular work routines.

Sampling was performed by randomly selecting 375 communities from AFKN. This number was selected by determining the size of the various knowledge communities and then developing a stratification for sampling. The community facilitators were contacted to determine whether they would allow their community to be surveyed. Once a commitment was obtained, the community's members became part of the candidate pool. Of the 375 communities, 157 agreed to be part of the study. The candidate pool consisted of 13,750 individuals and 1,115 invitations were sent to randomly selected members to obtain a minimum of 97 responses. The questionnaire was open and available for two weeks from April 27, 2010 to May 11, 2010.

The minimum sample size of 97 was determined by using a significance level of 0.05 , a power of 0.80 and a medium effect size of 0.15 . These parameters are common in social science and business research (Hair et al. 2017). In conjunction with the KMS-continuance model, these parameters resulted in a sample size of 85 , which was adjusted by $15 \%$ to compensate for measurement error, which made the minimum size 97 (Lehmann, 2006). 
G*Power 3 was used to determine the minimum sample size (Faul et al., 2009). While this sample size was sufficient to perform the PLS analysis on the KMS-continuance model, it fell short of the sample size needed to generalize the results to the AFKN population. A sample-size calculation was conducted to determine the sample size required to generalize the findings for the AFKN population of 300 thousand with a $5 \%$ margin of error. The result was a recommended sample of 384 .

The response rate was $19.7 \%$, with 221 complete responses. This is above the 97 required to test the KMScontinuance model but below the 384 responses needed to generalize to the AFKN population. As a result, the margin of error was increased to $6.9 \%$, making the required responses 202 . The respondents' demographic breakdown was as follows: $43.4 \%$ civilians, $22.2 \%$ officers and $34.4 \%$ enlisted personnel. Overall, $51.6 \%$ of the respondents used the repository features, $19.5 \%$ used the collaborative features, and $28.9 \%$ used the organizational process features. AFKN use tended to be voluntary and there were low rates of non-voluntary use. Table 2 displays the results.

Table 2: Sample Characteristics

\begin{tabular}{|c|c|c|}
\hline Variable & Count & Percentage \\
\hline \multicolumn{3}{|l|}{ Voluntary } \\
\hline Yes & 202 & 91.40 \\
\hline No & 19 & 8.60 \\
\hline \multicolumn{3}{|l|}{ Months of membership } \\
\hline Less than 1 & 4 & 1.81 \\
\hline 1 to 12 & 66 & 29.86 \\
\hline 13 to 24 & 52 & 23.53 \\
\hline 25 to 36 & 49 & 22.17 \\
\hline 37 to 48 & 22 & 9.95 \\
\hline 49 to 60 & 18 & 8.14 \\
\hline More than 60 & 10 & 4.52 \\
\hline \multicolumn{3}{|l|}{ Rank distribution } \\
\hline E-1 through E-4 (1) & 3 & 1.36 \\
\hline E-5 and E-6 (2) & 29 & 13.12 \\
\hline E-7 through E-9 (3) & 44 & 19.91 \\
\hline 0-1 through 0-3 (4) & 16 & 7.24 \\
\hline O-4 through 0-6 (5) & 33 & 14.93 \\
\hline 0-7 through 0-10 (6) & 0 & 0.00 \\
\hline GS-1 through GS-5 (7) & 0 & 0.00 \\
\hline GS-6 through GS-10 (8) & 3 & 1.36 \\
\hline GS-11 through GS-15 (9) & 6 & 2.71 \\
\hline Contractor (10) & 60 & 27.15 \\
\hline Other (11) & 27 & 12.22 \\
\hline \multicolumn{3}{|l|}{ Position } \\
\hline Facilitator & 19 & 8.60 \\
\hline Expert & 20 & 9.05 \\
\hline Leader & 35 & 15.84 \\
\hline Beginner & 54 & 24.43 \\
\hline Outsider & 27 & 12.22 \\
\hline Bystander & 66 & 29.86 \\
\hline \multicolumn{3}{|l|}{ Purpose of Community } \\
\hline Organization & 65 & 29.41 \\
\hline Project Team & 51 & 23.08 \\
\hline Functional Interest & 105 & 47.51 \\
\hline \multicolumn{3}{|l|}{ KMS Use } \\
\hline Repository & 114 & 51.58 \\
\hline Collaborative & 43 & 19.46 \\
\hline Process & 64 & 28.96 \\
\hline Total & 221 & \\
\hline
\end{tabular}

As part of the survey, respondents were asked to comment on factors that affected their decision to participate in their primarily community. The response was optional and no guidance was provided. The response results were grouped initially by whether the tenor of the response was positive or negative. After the initial 
assessment, the responses were grouped into six categories supported by a pilot study and a literature review. The thematic categories were repository performance, accessibility, content quality, organizational support, availability of time to access and collaboration. Overall, there were 96 comments from 76 individuals or $34.4 \%$ of the 221 respondents. Of the 96 comments, $42.7 \%$ were positive and $57.3 \%$ were negative. Table 3 displays the results of the open-comment responses.

Table 3: Open-Comment Response Summary

\begin{tabular}{|l|r|r|}
\hline Variable & Count & Percentage \\
\hline Positive or Negative & 41 & 42.71 \\
\hline Positive & 55 & 57.29 \\
\hline Negative & & 58.54 \\
\hline KMS Use (Positive) & 24 & 17.07 \\
\hline Repository & 7 & 24.39 \\
\hline Collaborative & 10 & \\
\hline Process & & 65.45 \\
\hline KMS Use (Negative) & 36 & 16.36 \\
\hline Repository & 9 & 18.18 \\
\hline Collaborative & 10 & 41.46 \\
\hline Process & & 12.20 \\
\hline Thematic Response (Positive) & 17 & 26.83 \\
\hline Repository Performance & 5 & 4.88 \\
\hline Accessibility & 11 & 2.44 \\
\hline Content Quality & 2 & 12.20 \\
\hline Organizational Support & 1 & \\
\hline Availability of Time & 5 & 0.00 \\
\hline Ability to Collaborate & & 41.82 \\
\hline Thematic Response (Negative) & 0 & 30.91 \\
\hline Repository Performance & 23 & 14.55 \\
\hline Accessibility & 17 & 10.91 \\
\hline Content Quality & 8 & 1.82 \\
\hline Organizational Support & 6 & 1 \\
\hline Availability of Time & 96 & \\
\hline Ability to Collaborate & & \\
\hline Total & & \\
\hline & & \\
\hline Pno & & \\
\hline
\end{tabular}

\section{Operationalization and Validation}

The data collection model, presented in Figure 2, highlights the relationship among the following ten variables: trust disconfirmation, network-ties disconfirmation, shared-language disconfirmation, system-quality disconfirmation, post-usage usefulness, satisfaction, IT self-efficacy, facilitating conditions, KMS-continuance intention, and continuance behavior. The variables based on previous research are presented in Section 3.2 and Table 1. The relationships shown in the model are tested by PLS using SmartPLS Version 3.0 (Ringle, Wende and Becker, 2015). SmartPLS provides an assessment of the measurement and structural models. SmartPLS provides $\mathrm{t}$-values and path coefficients for the measurement and structural models. It also provides an $\mathrm{R}^{2}$ for the structural model. Hypotheses are assessed based on the path coefficients of the structural model (Henseler et al., 2014).

\subsection{Measurement Model}

The assessed measurement model establishes model reliability and validity. The items evaluated as part of the measurement model are internal-consistency reliability and indicator reliability. Internal-consistency reliability indicates how well our items measure what they are expected to measure and are measured by evaluating the Cronbach's alphas, Rho alphas and the composite reliabilities of the variables shown in Table 4 (Fornell and Larcker, 1981; Hair et al., 2019; Sosik, Kahai and Piovoso, 2009). Internal-consistency reliability is 0.60 for exploratory research; however, there is a range of 0.70-0.95 for confirmatory research (Chin, 1998; Hair, 2009; Hair et al., 2019). Results above 0.95 indicate redundant variables. The ten variables have internal-consistency reliability values between 0.70 and 0.95 . 
Table 4: Composite Reliability, Cronbach's Alpha and Average Variance Extracted

\begin{tabular}{|c|c|c|c|c|c|c|c|c|}
\hline \# & Variables & $\begin{array}{c}\text { \# of } \\
\text { Items }\end{array}$ & Mean & SD & $\begin{array}{c}\text { Cronbach's } \\
\text { Alpha }\end{array}$ & $\begin{array}{c}\text { Rho } \\
\text { Alpha }\end{array}$ & $\begin{array}{c}\text { Composite } \\
\text { Reliability }\end{array}$ & AVE \\
\hline $\mathbf{1}$ & Facilitating Conditions (FC) & 3 & 4.91 & 1.43 & 0.83 & 0.83 & 0.83 & 0.63 \\
\hline $\mathbf{2}$ & IT Self-Efficacy (SE) & 3 & 5.11 & 1.27 & 0.89 & 0.89 & 0.89 & 0.73 \\
\hline $\mathbf{3}$ & KMS-Continuance Behavior (CB) & 3 & 2.25 & 1.39 & 0.82 & 0.82 & 0.82 & 0.61 \\
\hline $\mathbf{4}$ & KMS-Continuance Intention (Cl) & 3 & 5.66 & 1.05 & 0.95 & 0.96 & 0.95 & 0.87 \\
\hline $\mathbf{5}$ & Network-Ties (NT) Disconfirmation & 3 & 4.15 & 1.28 & 0.87 & 0.87 & 0.87 & 0.70 \\
\hline $\mathbf{6}$ & Post-Usage Usefulness (PU) & 4 & 4.98 & 1.26 & 0.93 & 0.94 & 0.93 & 0.78 \\
\hline $\mathbf{7}$ & Satisfaction (ST) & 3 & 5.27 & 1.16 & 0.90 & 0.91 & 0.90 & 0.76 \\
\hline $\mathbf{8}$ & Shared-Language (SL) Disconfirmation & 2 & 4.70 & 1.10 & 0.83 & 0.83 & 0.83 & 0.71 \\
\hline $\mathbf{9}$ & System-Quality (SQ) Disconfirmation & 3 & 4.69 & 1.27 & 0.78 & 0.78 & 0.78 & 0.55 \\
\hline $\mathbf{1 0}$ & Trust (T) Disconfirmation & 5 & 4.83 & 1.12 & 0.89 & 0.90 & 0.89 & 0.63 \\
\hline
\end{tabular}

Indicator reliability measures the proportion of each indicator's variance explained by the respective latent variable. An acceptable rule of thumb is that each item's loading should be 0.7 or greater (Hair et al., 2019). The bold items in Table 5 represent the loadings for the measurement model. All the loadings exceed the 0.7 threshold, which indicates acceptable reliability.

Construct validity of the measurement model is determined by evaluating factor loadings and cross-loadings while establishing convergent and discriminant validity. A generally accepted rule of thumb is to accept items with loadings of 0.7 or greater (Bollen, 1989). Bollen (1989) suggested that larger factor loadings indicate unidimensionality. In addition, items should load closely with their respective variables and load poorly with other variables. In this study, all items load well with their respective variables.

Convergent validity measures how well the measurement items relate to the variable (Campbell and Fiske, 1959). Convergent validity is established when the AVE is 0.5 or greater (Fornell and Larcker, 1981). AVE is a measure of the variance shared between the variable and its indicators. Each measurement item should load on its latent variable with a significant t-value (Chin, 1998). Table 4 indicates that all AVE range from 0.55 to 0.87.

Discriminant validity is established when each set of measurement items correlates weakly to other sets of measurement items (Campbell and Fiske, 1959). Discriminant validity is established when the square root of the AVE is consistently greater than the off-diagonal correlations. Discriminant validity can also be established by removing items that load poorly or appear to load on more than one variable. Table 6 reflects discriminate validity for all measurement items. Table 7 provides an evaluation of discriminate validity using the heterotraitmonotrait (HTMT) ratio. The desired HTMT ratio is 0.85 or less (Hair et al., 2019). The HTMT ratio is below 0.85 for all the latent variables.

Table 5: Loadings and Cross-Loadings

1) Facilitating Conditions, 2) IT Self-Efficacy, 3) KMS-Continuance Behavior, 4) KMS-Continuance Intention, 5) Network-Ties Disconfirmation, 6) Post-Usage Usefulness, 7) Satisfaction, 8) Shared-Language Disconfirmation, 9) System-Quality Disconfirmation, 10) Trust Disconfirmation

\begin{tabular}{|c|c|c|c|c|c|c|c|c|c|c|}
\hline Items & $\mathbf{1}$ & $\mathbf{2}$ & $\mathbf{3}$ & $\mathbf{4}$ & $\mathbf{5}$ & $\mathbf{6}$ & $\mathbf{7}$ & $\mathbf{8}$ & $\mathbf{9}$ & $\mathbf{1 0}$ \\
\hline FC6 & $\mathbf{0 . 7 8}$ & 0.35 & 0.34 & 0.33 & 0.31 & 0.35 & 0.46 & 0.21 & 0.36 & 0.29 \\
\hline FC7 & $\mathbf{0 . 8 0}$ & 0.29 & 0.39 & 0.41 & 0.20 & 0.38 & 0.42 & 0.19 & 0.36 & 0.22 \\
\hline FC8 & $\mathbf{0 . 7 9}$ & 0.32 & 0.41 & 0.43 & 0.17 & 0.43 & 0.40 & 0.10 & 0.31 & 0.17 \\
\hline SE1 & 0.38 & $\mathbf{0 . 8 6}$ & 0.32 & 0.43 & 0.11 & 0.53 & 0.64 & 0.13 & 0.57 & 0.26 \\
\hline SE2 & 0.31 & $\mathbf{0 . 8 2}$ & 0.28 & 0.35 & 0.20 & 0.57 & 0.60 & 0.13 & 0.60 & 0.32 \\
\hline SE3 & 0.35 & $\mathbf{0 . 8 8}$ & 0.37 & 0.37 & 0.22 & 0.58 & 0.62 & 0.21 & 0.64 & 0.37 \\
\hline CB1 & 0.34 & 0.28 & $\mathbf{0 . 7 7}$ & 0.50 & 0.16 & 0.41 & 0.32 & 0.03 & 0.26 & 0.19 \\
\hline CB2 & 0.38 & 0.32 & $\mathbf{0 . 7 9}$ & 0.41 & 0.25 & 0.44 & 0.33 & 0.14 & 0.33 & 0.25 \\
\hline CB3 & 0.40 & 0.29 & $\mathbf{0 . 7 7}$ & 0.40 & 0.27 & 0.36 & 0.27 & 0.26 & 0.26 & 0.28 \\
\hline CI1 & 0.45 & 0.36 & 0.47 & $\mathbf{0 . 9 0}$ & 0.23 & 0.69 & 0.59 & 0.12 & 0.33 & 0.27 \\
\hline CI2 & 0.52 & 0.47 & 0.58 & $\mathbf{1 . 0 1}$ & 0.25 & 0.71 & 0.64 & 0.16 & 0.44 & 0.29 \\
\hline CI3 & 0.40 & 0.42 & 0.51 & $\mathbf{0 . 8 9}$ & 0.20 & 0.68 & 0.54 & 0.19 & 0.40 & 0.31 \\
\hline NT1 & 0.22 & 0.15 & 0.25 & 0.21 & $\mathbf{0 . 8 4}$ & 0.29 & 0.24 & 0.47 & 0.31 & 0.53 \\
\hline NT2 & 0.21 & 0.17 & 0.26 & 0.18 & $\mathbf{0 . 8 2}$ & 0.32 & 0.32 & 0.48 & 0.38 & 0.49 \\
\hline NT3 & 0.28 & 0.19 & 0.22 & 0.22 & $\mathbf{0 . 8 5}$ & 0.37 & 0.33 & 0.42 & 0.37 & 0.51 \\
\hline
\end{tabular}




\begin{tabular}{|c|c|c|c|c|c|c|c|c|c|c|}
\hline Items & $\mathbf{1}$ & $\mathbf{2}$ & $\mathbf{3}$ & $\mathbf{4}$ & $\mathbf{5}$ & $\mathbf{6}$ & $\mathbf{7}$ & $\mathbf{8}$ & $\mathbf{9}$ & $\mathbf{1 0}$ \\
\hline PU1 & 0.47 & 0.64 & 0.47 & 0.61 & 0.36 & $\mathbf{0 . 9 0}$ & 0.69 & 0.27 & 0.61 & 0.4 \\
\hline PU2 & 0.46 & 0.59 & 0.47 & 0.62 & 0.38 & $\mathbf{0 . 8 9}$ & 0.68 & 0.28 & 0.56 & 0.45 \\
\hline PU3 & 0.37 & 0.53 & 0.45 & 0.61 & 0.37 & $\mathbf{0 . 8 3}$ & 0.61 & 0.28 & 0.56 & 0.45 \\
\hline PU4 & 0.43 & 0.55 & 0.43 & 0.79 & 0.28 & $\mathbf{0 . 9 1}$ & 0.71 & 0.23 & 0.56 & 0.38 \\
\hline ST1 & 0.44 & 0.56 & 0.31 & 0.58 & 0.37 & 0.63 & $\mathbf{0 . 8 4}$ & 0.21 & 0.66 & 0.40 \\
\hline ST2 & 0.53 & 0.69 & 0.32 & 0.56 & 0.28 & 0.70 & $\mathbf{0 . 9 1}$ & 0.17 & 0.73 & 0.40 \\
\hline ST3 & 0.43 & 0.64 & 0.40 & 0.53 & 0.28 & 0.66 & $\mathbf{0 . 8 6}$ & 0.22 & 0.68 & 0.41 \\
\hline SL1 & 0.14 & 0.16 & 0.19 & 0.12 & 0.49 & 0.29 & 0.18 & $\mathbf{0 . 8 6}$ & 0.32 & 0.53 \\
\hline SL2 & 0.22 & 0.15 & 0.12 & 0.17 & 0.44 & 0.22 & 0.20 & $\mathbf{0 . 8 3}$ & 0.38 & 0.52 \\
\hline SQ2 & 0.31 & 0.50 & 0.26 & 0.30 & 0.32 & 0.52 & 0.53 & 0.36 & $\mathbf{0 . 7 5}$ & 0.57 \\
\hline SQ3 & 0.34 & 0.56 & 0.22 & 0.30 & 0.24 & 0.47 & 0.64 & 0.30 & $\mathbf{0 . 7 3}$ & 0.42 \\
\hline SQ4 & 0.32 & 0.50 & 0.32 & 0.33 & 0.38 & 0.45 & 0.60 & 0.25 & $\mathbf{0 . 7 4}$ & 0.45 \\
\hline T1 & 0.21 & 0.30 & 0.23 & 0.21 & 0.50 & 0.35 & 0.32 & 0.46 & 0.47 & $\mathbf{0 . 7 5}$ \\
\hline T2 & 0.19 & 0.27 & 0.23 & 0.28 & 0.47 & 0.40 & 0.36 & 0.50 & 0.53 & $\mathbf{0 . 7 9}$ \\
\hline T3 & 0.22 & 0.30 & 0.18 & 0.21 & 0.56 & 0.35 & 0.39 & 0.49 & 0.50 & $\mathbf{0 . 7 9}$ \\
\hline T5 & 0.19 & 0.28 & 0.27 & 0.21 & 0.46 & 0.37 & 0.36 & 0.52 & 0.54 & $\mathbf{0 . 7 8}$ \\
\hline T7 & 0.32 & 0.32 & 0.31 & 0.31 & 0.44 & 0.44 & 0.41 & 0.48 & 0.53 & $\mathbf{0 . 8 5}$ \\
\hline
\end{tabular}

Table 6: Discriminant Validity

\begin{tabular}{|c|c|c|c|c|c|c|c|c|c|c|c|}
\hline$\#$ & Latent Variables & $\mathbf{1}$ & $\mathbf{2}$ & $\mathbf{3}$ & $\mathbf{4}$ & $\mathbf{5}$ & $\mathbf{6}$ & $\mathbf{7}$ & $\mathbf{8}$ & $\mathbf{9}$ & $\mathbf{1 0}$ \\
\hline $\mathbf{1}$ & Facilitating Conditions & $\mathbf{0 . 7 9}$ & & & & & & & & & \\
\hline $\mathbf{2}$ & IT Self-Efficacy & 0.40 & $\mathbf{0 . 8 5}$ & & & & & & & & \\
\hline $\mathbf{3}$ & KMS-Continuance Behavior & 0.48 & 0.38 & $\mathbf{0 . 7 8}$ & & & & & & & \\
\hline $\mathbf{4}$ & KMS-Continuance Intention & 0.49 & 0.45 & 0.56 & $\mathbf{0 . 9 3}$ & & & & & & \\
\hline $\mathbf{5}$ & Network-Ties Disconfirmation & 0.28 & 0.21 & 0.29 & 0.24 & $\mathbf{0 . 8 3}$ & & & & & \\
\hline $\mathbf{6}$ & Post-Usage Usefulness & 0.49 & 0.66 & 0.52 & 0.75 & 0.39 & $\mathbf{0 . 8 8}$ & & & & \\
\hline $\mathbf{7}$ & Satisfaction & 0.54 & 0.73 & 0.39 & 0.63 & 0.36 & 0.77 & $\mathbf{0 . 8 7}$ & & & \\
\hline $\mathbf{8}$ & Shared-Language Disconfirmation & 0.21 & 0.18 & 0.18 & 0.17 & 0.55 & 0.30 & 0.23 & $\mathbf{0 . 8 5}$ & & \\
\hline $\mathbf{9}$ & System-Quality Disconfirmation & 0.44 & 0.71 & 0.36 & 0.42 & 0.43 & 0.65 & 0.79 & 0.41 & $\mathbf{0 . 7 4}$ & \\
\hline $\mathbf{1 0}$ & Trust Disconfirmation & 0.29 & 0.37 & 0.31 & 0.31 & 0.61 & 0.48 & 0.46 & 0.62 & 0.65 & $\mathbf{0 . 7 9}$ \\
\hline
\end{tabular}

Table 7: Heterotrait-Monotrait Ratio

\begin{tabular}{|c|c|c|c|c|c|c|c|c|c|c|c|}
\hline$\#$ & Latent Variables & $\mathbf{1}$ & $\mathbf{2}$ & $\mathbf{3}$ & $\mathbf{4}$ & $\mathbf{5}$ & $\mathbf{6}$ & $\mathbf{7}$ & $\mathbf{8}$ & $\mathbf{9}$ & $\mathbf{1 0}$ \\
\hline $\mathbf{1}$ & Facilitating Conditions & & & & & & & & & & \\
\hline $\mathbf{2}$ & IT Self-Efficacy & 0.40 & & & & & & & & & \\
\hline $\mathbf{3}$ & KMS-Continuance Behavior & 0.48 & 0.38 & & & & & & & & \\
\hline $\mathbf{4}$ & KMS-Continuance Intention & 0.49 & 0.45 & 0.56 & & & & & & & \\
\hline $\mathbf{5}$ & Network-Ties Disconfirmation & 0.28 & 0.21 & 0.29 & 0.24 & & & & & & \\
\hline $\mathbf{6}$ & Post-Usage Usefulness & 0.49 & 0.66 & 0.52 & 0.75 & 0.39 & & & & & \\
\hline $\mathbf{7}$ & Satisfaction & 0.53 & 0.72 & 0.40 & 0.63 & 0.36 & 0.76 & & & & \\
\hline $\mathbf{8}$ & Shared-Language Disconfirmation & 0.21 & 0.18 & 0.19 & 0.17 & 0.55 & 0.30 & 0.23 & & & \\
\hline $\mathbf{9}$ & System-Quality Disconfirmation & 0.44 & 0.71 & 0.36 & 0.42 & 0.43 & 0.65 & 0.79 & 0.41 & & \\
\hline $\mathbf{1 0}$ & Trust Disconfirmation & 0.29 & 0.37 & 0.31 & 0.31 & 0.61 & 0.48 & 0.46 & 0.62 & 0.65 & \\
\hline
\end{tabular}

\subsection{Structural Model Assessment}

The structural model was assessed by estimating the variance $\left(R^{2}\right.$ values) and the path coefficients. The $R^{2}$ values measure the model's predictive power in relation to the dependent variables (Chin, 1998; Chin, Marcolin and Newsted, 2003). The level of $R^{2}$ is explained differently in the literature. Falk and Miller (1992) considered an $R^{2}$ from 0.11 to 0.75 as significant. Chin (1998) and Chin, Marcolin and Newsted (2003) developed different categories to explain $R^{2}$ significance levels with an $R^{2}$ of greater than 0.67 considered substantial, 0.33 to 0.67 moderate and 0.19 to 0.33 weak. Hair et al. (2019) referred to $R^{2}$ values of $0.75,0.50$ and 0.25 as substantial, moderate, and weak, respectively.

Path coefficients indicate the strength of the relationships between the different variables tested in the model. T-values were used in the measurement model and the structural model to determine the significance of the paths. The path coefficients were estimated using the consistent bootstrapping method with the recommended sample size-500 initially and 5,000 for finalization (Chin, 1998; Dijkstra and Henseler, 2015). Significant path relationships indicate support for the hypotheses (Bentler, 1985). Chin, Marcolin and Newsted (2003) 
recommended that standardized paths be at least 0.20 and stated that they should be 0.30 to be considered meaningful.

The model results shown in Figure 3 indicate that two significant paths meet the recommended 0.20 cutoff and five significant paths exceed the recommended 0.30 cutoff. Seven paths fall below the 0.20 cutoff. The variance explained by trust, network-ties, shared-language and system-quality disconfirmation to post-usage usefulness is $44 \%$ and satisfaction is $65 \%$. The pathways from trust, shared-language and network-ties disconfirmation to post-usage usefulness and satisfaction are not significant at the $p=0.05$ level. The pathways from system-quality disconfirmation to post-usage usefulness and satisfaction are all significant at the $p=0.05$ level. System-quality disconfirmation also has a significant pathway to network-ties disconfirmation at the $p=0.05$ level. The variance explained by the pathway from system-quality disconfirmation to network-ties disconfirmation is $18 \%$. The variance of KMS-continuance intention explained by post-usage usefulness, satisfaction and IT self-efficacy is $58 \%$. The pathways from post-usage usefulness and satisfaction are significant at the $p=0.05$ level. The pathway from IT self-efficacy to KMS-continuance intention is insignificant. The amount of variance explained by KMScontinuance intention is moderate based on Chin, Marcolin and Newsted (2003). The variance obtained this study is similar to the research on information systems conducted by Bhattacherjee, Perols and Sandford (2008) and in Chen's (2007) KMS research. The amount of variances of KMS-continuance behavior explained by continuance intention and facilitating conditions is $37 \%$. The pathways from KMS-continuance intention to continuance behavior and from facilitating conditions to KMS-continuance behavior are both significant at the $p=0.05$ level. According to Chin's criteria (1998), the variance explained is weak to moderate. The variance from intention to action in this study is similar to previous information systems continuance research (Bhattacherjee, Perols and Sandford, 2008). This result suggests that the KMS-continuance model functions similarly to previous information-systems research. Table 8 presents a summary of the hypotheses.

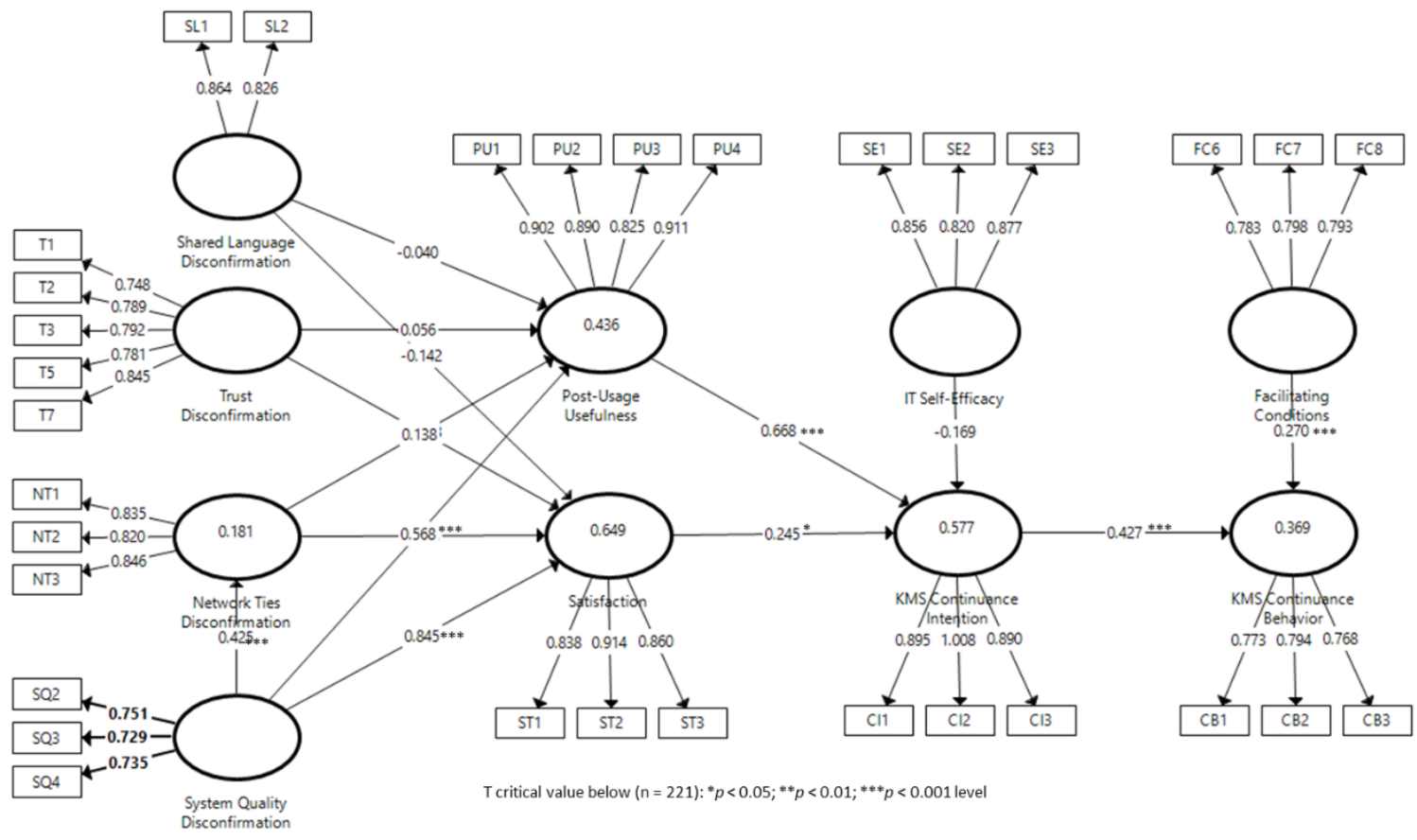

Figure 3: Knowledge Management System Continuance PLS Model Results 
Table 8: Summary of Hypotheses

\begin{tabular}{|l|c|c|c|}
\hline \multicolumn{1}{|c|}{ Structural Path } & $\begin{array}{c}\text { Standardized Path } \\
\text { Coefficients }\end{array}$ & T-Value & Supported \\
\hline H1A: Post-Usage Usefulness $\rightarrow$ KMS-Continuance Intention & $0.67^{* * *}$ & 7.78 & Yes \\
\hline H1B: Satisfaction $\rightarrow$ KMS-Continuance Intention & $0.25^{*}$ & 2.24 & Yes \\
\hline H2: KMS-Continuance Intention $\rightarrow$ KMS-Continuance Behavior & $0.43^{* * *}$ & 6.64 & Yes \\
\hline H3A: Trust Disconfirmation $\rightarrow$ Post-Usage Usefulness & 0.06 & 0.05 & No \\
\hline H3B: Trust Disconfirmation $\rightarrow$ Satisfaction & -0.06 & 0.55 & No \\
\hline H3C: Network-Ties Disconfirmation $\rightarrow$ Post-Usage Usefulness & 0.14 & 1.33 & No \\
\hline H3D: Network-Ties Disconfirmation $\rightarrow$ Satisfaction & 0.11 & 1.39 & No \\
\hline H3E: Shared-Language Disconfirmation $\rightarrow$ Post-Usage Usefulness & -0.04 & 0.43 & No \\
\hline H3F: Shared-Language Disconfirmation $\rightarrow$ Satisfaction & -0.14 & 1.73 & No \\
\hline H4A: System-Quality Disconfirmation $\rightarrow$ Network-Ties Disconfirmation & $0.43^{* * *}$ & 4.58 & Yes \\
\hline H4B: System-Quality Disconfirmation $\rightarrow$ Post-Usage Usefulness & $0.57^{* * *}$ & 4.83 & Yes \\
\hline H4C: System-Quality Disconfirmation $\rightarrow$ Satisfaction & $0.85^{* * *}$ & 9.21 & Yes \\
\hline H5: IT Self-Efficacy $\rightarrow$ KMS-Continuance Intention & -0.17 & 1.69 & No \\
\hline H6: Facilitating Conditions $\rightarrow$ KMS-Continuance Behavior & $0.27^{* * *}$ & 3.44 & Yes \\
\hline
\end{tabular}

${ }^{*} p<0.05 ;{ }^{* *} p<0.01 ;{ }^{* * *} p<0.001$ (two-tailed)

\section{Discussion and Conclusions}

This study examined what influences a person to become a continuous user of a KMS by studying continuance behavior. The results show that the community and technology dimensions affect a user's evaluation of the KMS. Additionally, individual attitudes and organizational support are important influencers, but their influence is not even. The findings, limitations and the needs of practitioners and academia are addressed in this section.

This study examined the community dimensions of trust, network ties and shared language using a disconfirmation approach. These dimensions were based on social capital theory and were expected to work together to influence a user's evaluation of the KMS (Nahapiet and Ghoshal, 1998). In this examination, all the community dimensions indicated few or no significant pathways to influencing the user's post-usage usefulness evaluation. In contrast to the community dimension, the technology dimension positively influences both postusage usefulness and satisfaction. While members may have had limited experience with the system's community features, many were clear in their system-quality disconfirmation answers. Whether a user belongs to a community or not, they all require technology to access the KMS. Additionally, system-quality disconfirmation positively influences the community dimension of network-ties disconfirmation. The data show that users' experience with the system's technology affects how network ties are formed. However, as previously noted, while network-ties disconfirmation mediates system-quality disconfirmation, it does not significantly affect post-usage usefulness or satisfaction. According to the results, the community dimensions appear to have minimal influence on the user's evaluation. Although these variables should have influenced the user's evaluation, they did not. These variables may not be salient in the users' minds based on the culture of the Air Force and the openness of the AFKN system. Based on these results, additional investigation is needed to understand better when the community dimension of KMSs becomes a significant factor.

User evaluations in the form of satisfaction and post-usage usefulness significantly influence an individual's KMScontinuance intention. Post-usage usefulness has a more substantial influence than satisfaction on KMScontinuance intention. This indicates that an individual's continuance-intention decision is based on a holistic evaluation of the KMS versus short-term gratification. This finding aligns with previous studies showing that post-usage usefulness is less time sensitive and a more robust indicator of future action (LaTour and Peat, 1980). KMS-continuance intention is a significant influence on KMS-continuance behavior. While an intention-to-action gap exists in the current study, the $37 \%$ of variance explained by intentions on behavior is similar to previous information system research (Bhattacherjee, Perols and Sandford, 2008). Lastly, given the functional nature of KMS use, a gap in intention to use should be expected, as frequency-based measures are not the best way to measure the actual use of a KMS. This finding aligns with Jennex (2017), who suggested that actual use will occur when appropriate.

Individual and organizational dimensions were examined using IT self-efficacy and facilitating conditions. IT selfefficacy was expected to influence KMS-continuance intention; however, the data did not support this expectation. In the research by Bhattacherjee, Perols and Sandford (2008), IT self-efficacy influenced 
information system continuance intentions. Facilitating conditions were established in previous research to model external resources' influence and were expected to influence KMS-continuance behavior (Bhattacherjee, Perols and Sandford, 2008; Venkatesh, et al., 2003). Facilitating conditions, as used in this study, added additional factors to explore other dimensions viewed as external resources. Facilitating conditions influence the KMS-continuance behavior by $5 \%$.

Another finding indicates that individuals have limited time to use a KMS; however, when they use the system, they use it to access updated repositories and work-process features. Unfortunately, several respondents indicated that their ability to access and navigate the KMS was low and that the information in the KMS was not maintained. Respondents who said they used the collaborative system features found the tools too cumbersome. As a result, individuals often sent emails rather than using more collaborative tools such as chat, discussion forums and web conferencing. Respondents noted that the networking features were useful but still too immature to work effectively. This feedback is helpful for developers looking to increase system's accessibility and usability.

Furthermore, research was needed to determine how and why an individual becomes a continuous user of a KMS in order to reduce system-failure rates (Kerno, 2008; Tseng, 2008). The analysis shows that quality is a significant factor influencing an individual's evaluation of a system. Users indicated that curation of quality content and system accessibility are important factors influencing their continued use. Accessing the system in the study required a card interface. This feature limits the time that users can spend on the system. Unless individuals have the same home accessibility as work accessibility, they are less likely to participate and become continuous users. Additionally, users must know which features are available, how to access them and these features must be convenient to use.

One limitation of this study lies in the demographics of the survey group. According to the data, approximately $19.5 \%$ of the respondents used collaborative features. Additionally, the results of the community-dimension questions had a non-significant impact in the analysis. These two combinations limit the understanding of those who use the KMS collaboratively.

Additionally, KMS users who mainly use the repository and process features may have different needs from those using the collaborative features. This effort studied a wide range of users. More research is needed to focus on users who use the collaborative features of the KMS. The analysis of the specific KMS-usage approach showed no difference when compared to the entire sample. While theory supported the development of the community dimension, the results in this study were limited and more research is needed.

The current study used self-reporting frequency measures of usage. This approach may not accurately indicate an individual's actual usage. However, measuring KMS usage by a non-frequency-based measure may be a better indicator than a frequency-based measure extracted from archival data given the use-as-needed nature of KMSs.

Another limitation of this study is the lack of responses from the highest-ranking individuals in the organization. While there are senior executives who have access to the system, none responded to the survey. An examination of how senior individuals use a KMS is of interest. A dimension that could be examined is the impact of seniorlevel leadership's using the KMS on the actual use by less senior individuals in the organization

Future research should employ a two-step approach that establishes a baseline of initial expectations followed by a disconfirmation measure. This approach has been used in past research efforts that employed the disconfirmation method (Chen, 2007). Future studies could also investigate the link between continuance behavior and other performance outcomes at the individual, team and organizational levels.

Finally, the research results indicate that practitioners of KMSs must ensure their systems are accessible, the available functions are clear and the content is curated and of high quality. Additionally, practitioners must ensure that the use of the KMS is integrated into organizational processes so their members have designated time and resources to participate. For academia, this study expands the literature on continuance behavior in relation to KMS. It also indicates several additional dimensions for study, including the collaborative dimensions of KMSs, senior executive participation and an approach that can be connected to organizational outcome metrics to determine whether KMS use impacts performance. 


\section{Disclosure statement}

The views expressed in this presentation are those of the authors and do not necessarily reflect the official policy or position of the Air Force, the Department of Defense, or the US Government. Distribution A: Approved for Public Release, Distribution Unlimited. USAFA-DF-2020-388.

\section{References}

Ajzen, I., 1985. From intentions to actions: a theory of planned behavior. In: J. Beckmann and J. Kuhl, eds. Action control, from cognition to behavior. New York, NY: Springer-Verlag.pp.11-39.

Ajzen, I., 1991. The theory of planned behavior. Organizational Behavior \& Human Decision Processes, 50(2), pp.179-211.

Alavi, M. and Leidner, D.E., 2001. Review: knowledge management and knowledge management systems: conceptual foundations and research issues. MIS Quarterly, 25(1), pp.107-136.

Anderson, E.W. and Sullivan, M.W., 1993. The antecedents and consequences of customer satisfaction for firms. Marketing Science, 12(2), pp.125-143.

Ardichvili, A., 2008. Learning and knowledge sharing in virtual communities of practice: motivators, barriers, and enablers. Advances in Developing Human Resources, 10(4), pp.541-554.

Argote, L., McEvily, B. and Reagans, R., 2003. Managing knowledge in organizations: an integrative framework and review of emerging themes. Management Science, 49(4, Special Issue on Managing Knowledge in Organizations: Creating, Retaining, and Transferring Knowledge), pp.571-582.

Bartczak, S.E., Turner, J.M. and England, E.C., 2008. Challenges in developing a knowledge management strategy: a case study of the air force materiel command1. International Journal of Knowledge Management, 4(1), pp.46-50.

Bentler, P.M., 1985. Theory and implementation of eqs: a structural equations program. Los Angeles, CA: BMDP Statistical Software.

Bhattacherjee, A., 2001. Understanding information systems continuance: an expectation-confirmation model. MIS Quarterly, 25(3), pp.351-370.

Bhattacherjee, A., Perols, J. and Sandford, C., 2008. Information technology continuance: a theoretic extension and empirical test. Journal of Computer Information Systems, 49(1), pp.17-26.

Binney, D., 2001. The knowledge management spectrum - understanding the km landscape. Journal of Knowledge Management, 5(1), pp.33-42.

Bolisani, E. and Handzic, M., 2014. Advances in knowledge management: celebrating twenty years of research and practice. Cham, SWITZERLAND: Springer International Publishing AG.

Bollen, K.A., 1989. A new incremental fit index for general structural equation models. Sociological Methods \& Research, 17(3), pp.303-316.

Campbell, D.T. and Fiske, D.W., 1959. Convergent and discriminant validation by the multitrait-multimethod matrix. Psychological bulletin, 56(2), pp.81-105.

Cepeda-Carrion, G., Cegarra-Navarro, J.-G. and Cillo, V., 2019. Tips to use partial least squares structural equation modelling (pls-sem) in knowledge management. Journal of Knowledge Management, 23(1), pp.67-89.

Chen, I.Y.L., 2007. The factors influencing members' continuance intentions in professional virtual communities-a longitudinal study. Journal of Information Science, 33(4), pp.451-467.

Chin, W.W., 1998. The partial least squares approach to structural equation modeling. In: G.A. Marcoulides, ed. Modern methods for business research. Mahwah, NJ: Lawrence Erlbaum.pp.295-336.

Chin, W.W., Marcolin, B.L. and Newsted, P.R., 2003. A partial least squares latent variable modeling approach for measuring interaction effects: results from a monte carlo simulation study and an electronic-mail emotion/adoption study. Information Systems Research, 14(2), pp.189-217.

Clay, P.F., Dennis, A.R. and Ko, D.-G., 2005. Factors affecting the loyal use of knowledge management systems. In: Proceedings of the 38th Annual Hawaii International Conference on System Sciences. pp.251c-251c.

Compeau, D.R. and Higgins, C.A., 1995. Application of social cognitive theory to training for computer skills. Information Systems Research, 6(2), pp.118-143.

Cooper, R.B. and Zmud, R.W., 1990. Information technology implementation research: a technological diffusion approach. Management Science, 36(2), pp.123-139.

Davenport, T.H., De Long, D.W. and Beers, M.C., 1998. Successful knowledge management projects. Sloan management review, 39(2), pp.43-57.

Davenport, T.H. and Prusak, L., 1998. Working knowledge: how organizations manage what they know. Boston, MA: Harvard Business School Press.

Davis, F.D., 1989. Perceived usefulness, perceived ease of use, and user acceptance of information technology. MIS Quarterly, 13(3), pp.319-340.

Dijkstra, T.K. and Henseler, J., 2015. Consistent partial least squares path modeling. MIS quarterly, 39(2), pp.297-316.

Earl, M., 2001. Knowledge management strategies: toward a taxonomy. Journal of Management Information Systems, 18(1), pp.215-233.

Falk, R.F. and Miller, N.B., 1992. A primer for soft modeling. Akron, OH: University of Akron Press.

Faul, F., Erdfelder, E., Buchner, A. and Lang, A.-G., 2009. Statistical power analyses using g* power 3.1: tests for correlation and regression analyses. Behavior research methods, 41(4), pp.1149-1160. 
Fitzgerald, D.C., 2004. An exploratory analysis of factors affecting participation in air force knowledge now communities of practice. Thesis.

Fornell, C. and Larcker, D.F., 1981. Structural equation models with unobservable variables and measurement error: algebra and statistics. Journal of Marketing Research (JMR), 18(3), pp.382-388.

Gold, A.H., Malhotra, A. and Segars, A.H., 2001. Knowledge management: an organizational capabilities perspective. Journal of Management Information Systems, 18(1), pp.185-214.

Goodhue, D.L. and Thompson, R.L., 1995. Task-technology fit and individual performance. MIS quarterly, pp.213-236.

Hair, J.F., 2009. Multivariate data analysis. Upper Saddle River, NJ: Prentice Hall.

Hair, J.F., Risher, J.J., Sarstedt, M. and Ringle, C.M., 2019. When to use and how to report the results of pls-sem. European Business Review, 31(1), pp.2-24.

Hansen, M.T., Nohria, N. and Tierney, T., 1999. What's your strategy for managing knowledge? Harvard business review, 77(2), pp.106-116.

$\mathrm{He}, \mathrm{W}$. and Wei, K.-K., 2006. Knowledge management systems (kms) continuance in organizations: a social relational perspective. In: International Conference on Knowledge Science, Engineering and Management. Springer, Berlin, Heidelberg.pp.34-41.

He, W. and Wei, K.-K., 2009. What drives continued knowledge sharing? An investigation of knowledge-contribution andseeking beliefs. Decision Support Systems, 46(4), pp.826-838.

Heisig, P., Suraj, O.A., Kianto, A., Kemboi, C., Arrau, G.P. and Easa, N.F., 2016. Knowledge management and business performance: global experts' views on future research needs. Journal of Knowledge Management, 20(6), pp.11691198.

Henseler, J., Dijkstra, T.K., Sarstedt, M., Ringle, C.M., Diamantopoulos, A., Straub, D.W., Ketchen, D.J., Hair, J.F., Hult, G.T. and Calantone, R.J., 2014. Common beliefs and reality about pls: comments on rönkkö and evermann (2013). Organizational Research Methods, 17(2), pp.182-209.

Jennex, M., 2012. Identifying the components of a knowledge management strategy. AMCIS 2012. Seattle, Washington.pp.1-9.

Jennex, M., 2017. Re-examining the jennex olfman knowledge management success model. In: Proceedings of the 50th Hawaii International Conference on System Sciences. pp.4375-4384.

Jennex, M.E. and Olfman, L., 2006. A model of knowledge management success. International Journal of Knowledge Management (IJKM), 2(3), pp.51-68.

Kalling, T., 2003. Knowledge management and the occasional links with performance. Journal of Knowledge Management, 7(3), pp.67-81.

Kerno, J.S.J., 2008. Tapping communities of practice. Mechanical Engineering, 130(10), pp.22-27.

Krogh, G.V., Nonaka, I. and Aben, M., 2001. Making the most of your company's knowledge: a strategic framework. Long range planning, 34(4), pp.421-439.

Kwon, T.H. and Zmud, R.W., 1987. Unifying the fragmented models of information systems implementation. In: R. Boland and R.A. Hirschheim, eds. Critical issues in information systems research, John Wiley information systems series. New York, NY: Wiley.pp.227-251.

LaTour, S.A. and Peat, N.C., 1980. The role of situationally-produced expectations, others' experiences, and prior experience in determining customer satisfaction. In: J. Olson, ed. Advances in Consumer Research. pp.588-592.

Lehaney, B., Lovett, P. and Shah, M., 2011. Business information systems and technology: a primer. Florence, UNITED STATES: Taylor \& Francis Group.

Lehmann, E.L., 2006. Nonparametrics: statistical methods based on ranks. 1st ed. New York, NY: Springer.

Lin, C. and Tseng, S.-M., 2005. Bridging the implementation gaps in the knowledge management system for enhancing corporate performance. Expert Systems with Applications, 29(1), pp.163-173.

Lucas, H.C., 1990. Information systems concepts for management. 4th ed. New York: Mitchell McGraw-Hill.

Maier, R., 2007. Knowledge management systems: information and communication technologies for knowledge management. Berlin, Heidelberg, Germany: Springer Berlin / Heidelberg.

Malhotra, Y., 2005. Integrating knowledge management technologies in organizational business processes: getting real time enterprises to deliver real business performance. Journal of Knowledge Management, 9(1), pp.7-28.

Mathieson, K., 1991. Predicting user intentions: comparing the technology acceptance model with the theory of planned behavior. Information Systems Research, 2(3), pp.173-191.

McKeen, J.D., Zack, M.H. and Singh, S., 2006. Knowledge management and organizational performance: an exploratory survey. In: Proceedings of the 39th Annual Hawaii International Conference on System Sciences. pp.152b-152b.

McKinney, V., Yoon, K. and Zahedi, F., 2002. The measurement of web-customer satisfaction: an expectation and disconfirmation approach. Information Systems Research, 13(3), pp.296-315.

McKnight, D.H., Choudhury, V. and Kacmar, C., 2002. Developing and validating trust measures for e-commerce: an integrative typology. Information Systems Research, 13(3), pp.334-359.

Nahapiet, J. and Ghoshal, S., 1998. Social capital, intellectual capital, and the organizational advantage. Academy of Management Review, 23(2), pp.242-266.

Nisar, T.M., Prabhakar, G. and Strakova, L., 2019. Social media information benefits, knowledge management and smart organizations. Journal of Business Research, 94, pp.264-272.

Nonaka, I., 1994. A dynamic theory of organizational knowledge creation. Organization Science, 5(1), pp.14-37. 
O'Dell, C. and Grayson, C.J., 1998. If only we knew what we know: identification and transfer of internal best practices. California management review, 40(3), pp.154-174.

Oliver, R.L., 1980. A cognitive model of the antecedents and consequences of satisfaction decisions. Journal of marketing research, 17(4), pp.460-469.

Oliver, R.L., 1993. Cognitive, affective, and attribute bases of the satisfaction response. Journal of Consumer Research, 20(3), pp.418-430.

Prusak, L. and Cohen, D., 2001. How to invest in social capital. Harvard business review, 79(6), pp.86-97.

Ringle, C.M., Wende, S. and Becker, J.-M., 2015. SmartPLS 3. Boenningstedt: SmartPLS GmbH.

Rogers, E.M., 2003. Diffusion of innovations. 5th ed. New York, NY: Free Press.

Schiuma, G., Andreeva, T. and Kianto, A., 2012. Does knowledge management really matter? Linking knowledge management practices, competitiveness and economic performance. Journal of knowledge management, 16(4), pp.617-636.

Small, C.T. and Sage, A.P., 2006. Knowledge management and knowledge sharing: a review. Information Knowledge Systems Management, 5(3), pp.153-169.

Smith, T.A., Mills, A.M. and Dion, P., 2010. Linking business strategy and knowledge management capabilities for organizational effectiveness. International Journal of Knowledge Management (IJKM), 6(3), pp.22-43.

Sosik, J.J., Kahai, S.S. and Piovoso, M.J., 2009. Silver bullet or voodoo statistics? A primer for using the partial least squares data analytic technique in group and organization research. Group \& Organization Management, 34(1), pp.5-36.

Spreng, R.A., MacKenzie, S.B. and Olshavsky, R.W., 1996. A reexamination of the determinants of consumer satisfaction. Journal of Marketing, 60(3), pp.15-32.

Taylor, S. and Todd, P., 1995a. Assessing it usage: the role of prior experience. MIS Quarterly, 19(4), pp.561-570.

Taylor, S. and Todd, P.A., 1995b. Understanding information technology usage: a test of competing models. Information Systems Research, 6(2), pp.144-176.

Thompson, R.L., Higgins, C.A. and Howell, J.M., 1991. Personal computing: toward a conceptual model of utilization. MIS quarterly, pp.125-143.

Tiwana, A. and Bush, A.A., 2005. Continuance in expertise-sharing networks: a social perspective. IEEE Transactions on Engineering Management, 52(1), pp.85-101.

Triandis, H.C., 1979. Values, attitudes, and interpersonal behavior. Nebraska Symposium on Motivation, 27, pp.195-259.

Tseng, S.-M., 2008. Knowledge management system performance measure index. Expert Systems with Applications, 34(1), pp.734-745.

Venkatesh, V. and Davis, F.D., 2000. A theoretical extension of the technology acceptance model: four longitudinal field studies. Management Science, 46(2), pp.186-204.

Venkatesh, V., Morris, M.G., Davis, G.B. and Davis, F.D., 2003. User acceptance of information technology: toward a unified view. MIS Quarterly, 27(3), pp.425-478.

Wang, Y.-M. and Wang, Y.-C., 2016. Determinants of firms' knowledge management system implementation: an empirical study. Computers in Human behavior, 64, pp.829-842.

Wiig, K.M., 1997. Knowledge management: an introduction and perspective. Journal of Knowledge Management, 1(1), pp.6-14.

Wold, H., 1985. Systems analysis by partial least squares. In: P. Nijkamp, H. Leitner and N. Wrigley, eds. Measuring the unmeasurable, NATO ASI series, no. 22. Dordrecht, The Netherlands: Marinus Nijhoff.pp.221-251. 